\title{
How Many Thymic Epithelial Cells Are Necessary for a Proper Maturation of Thymocytes?
}

\author{
Sara Montero-Herradón ${ }^{1,2 \dagger}$, Javier García-Ceca ${ }^{1,2 \dagger}$ and Agustín G. Zapata ${ }^{1,2 *}$ \\ ${ }^{1}$ Department of Cell Biology, Faculty of Biology, Complutense University of Madrid, Madrid, Spain, ${ }^{2}$ Health Research \\ Institute, Hospital 12 de Octubre (imas12), Madrid, Spain
}

Keywords: thymic epithelial cells, thymocyte education, Eph, ephrin, regulatory T-cells

\section{INTRODUCTION}

The central tolerance to self-antigens is achieved in the thymus through a complex process in which developing thymocytes (T) sequentially interact with thymic epithelial cells (TECs) in a 3D network histologically organized in a cortex and a medulla (1). This T-TEC crosstalk is assumed to be essential for performing the named thymocyte education (2).

\section{OPEN ACCESS}

Edited by:

Marita Bosticardo,

National Institutes of Health $(\mathrm{NIH})$,

United States

Reviewed by:

Pärt Peterson,

University of Tartu, Estonia

*Correspondence:

Agustín G. Zapata

zapata@bio.ucm.es

tThese authors have contributed equally to this work

Specialty section:

This article was submitted to

T Cell Biology,

a section of the journal

Frontiers in Immunology

Received: 16 October 2020 Accepted: 16 February 2021

Published: 08 March 2021

Citation:

Montero-Herradón S, García-Ceca J and Zapata AG (2021) How Many

Thymic Epithelial Cells Are Necessary

for a Proper Maturation of

Thymocytes?

Front. Immunol. 12:618216.

doi: 10.3389/fimmu.2021.618216

\section{IS T-CELL MATURATION POSSIBLE IN AN ALTERED THYMIC EPITHELIAL MICROENVIRONMENT?}

There are examples in the literature showing that profound alterations of the thymic epithelial organization, which course with total or partial absence of T-TEC interactions mediated by distinct experimental conditions, do no result in important changes in the phenotype of T-cell subsets or in a breakage of central tolerance.

Revest et al. (3) demonstrated that FGF signaling was essential for TEC proliferation and that its lack coursed with low numbers of TECs that presumably would established reduced T-TEC interactions. However, in these conditions, phenotypical intrathymic lymphoid cell differentiation occurred normally, producing both DP and SP thymocytes. Authors remarked that even a low number of TECs would establish sufficient T-TEC interactions for supporting, at least phenotypical, lymphoid cell maturation. In a similar way, mice deficient in p63, a homolog of the p53 tumor suppressor gene involved in the morphogenesis and maintenance of thymic epithelium and epidermis, exhibit hypoplasia with increased proportions of apoptotic cells but normal T-cell development (4).

The Kremen (Krm) family of proteins that interact with the secreted Wnt regulator Dickkopf (Dkk) is considered a specific inhibitor of the canonical Wnt signaling pathway $(5,6)$. The loss of Krm1, that results in an excessive canonical Wnt signaling, induces profound alterations of the thymic architecture including incomplete separation of cortex and medulla, big epithelial free areas (EFAs), increased numbers of immature $\mathrm{K}^{+}{ }^{+} \mathrm{K}^{+}$TECs and loss of cell processes in cortical (c) TECs, that undoubtedly affect the T-TEC crosstalk. However, the lack of Krm1 gene had no effects on the numbers and proportions of thymocytes (7). Accordingly, authors speculated that the histological organization of the thymus might be less relevant for the T-cell maturation than the mere occurrence of different TEC subsets. On the other hand, the presence of small groups of TECs properly organized from a histological view and expressing key molecules involved in the functional crosstalk between TECs and thymocytes would be sufficient to allow the thymocyte differentiation in mutant thymuses $(3,7)$. In addition, Benz and colleagues (8) used other experimental approach to demonstrate that in CCR9-deficient thymuses DN2 and DN3 thymocytes did not migrate and 
occupy the subcapsular cortex but developed normally, questioning the relevance of thymic niches that could just optimize the T-cell maturation rather than being a mandatory requisite for achieving the process. More recently, Cosway et al. (9) reported maintenance of T-cell tolerance in mice with a specific deletion of lymphotoxin $\beta$ receptor (LT $\beta$ R) gene in TECs that exhibited profound alterations of thymic medulla. In this case, dendritic cells (DCs) rather than medullary TECs appeared to be supporting the negative selection (10).

\section{THE CONDITION OF EphB-DEFICIENT THYMUSES}

In the last years, we have analyzed the role of tyrosine kinase receptors of the family Eph (Erythropoietin-producing hepatocyte) and their ligands ephrins (Eph receptor-interacting proteins) in the biology of the thymus. Eph-ephrin signaling participates in numerous processes in the immune and other tissues through the modulation of cell attachment, detachment, migration, proliferation, differentiation and cell fate (11). Our results, which have been summarized several times (12-14), confirm a role for EphB2, EphB3, ephrin-B1, and ephrin-B2 in the development and homeostasis of thymic epithelium. In these studies, as in those previously reported, we demonstrated that altered thymic epithelial network, which partially blocked the TTEC interactions, does not course irrefutably with remarkable changes in the functional maturation of thymocytes, including both positive and negative selection (13).

On the other hand, the absence of these molecules clearly affected the T-TEC interactions. The mere morphological analysis of EphB-deficient thymuses suggested difficulties for establishing T-TEC contacts: scattered at random medullary epithelial islets, existence of large EFAs, retracted and disappeared epithelial cell processes (12). On the other hand, lymphoid progenitor cells differentiate in grafted EphB-deficient thymic lobes (15) and in vitro treatment of thymic reaggregates (RTOCs) with anti-EphB2 or anti-EphB3 specific antibodies shortened the TEC processes (13). The named thymic nurse cells (TNC) are cell complexes consisting of a single cTEC that homes 7-50 thymocytes and constitute specialized thymic niches for T-cell maturation (16). TNCs derived from EphB-deficient thymuses exhibit significantly reduced numbers of the most frequent ones containing 6-10 thymocytes (13). In fact, Eph and ephrin modulate both kinetic of cell conjugated established between DP thymocytes and isolated TECs and the formation of functional immunological synapsis $(17,18)$. Together all these results justify that the lack of Eph and ephrin signals alters the cellular positioning making it impossible that, as reported in other tissues, for thymocytes and TECs to intermingle and interact.

In agreement with all these data, we recently analyzed the T-cell populations of EphB2- or EphB3-deficient mice observing no phenotypical changes in the proportions of Tcell subsets phenotypically defined by specific cell markers $(13,19)$. Previously, we reported delayed maturation of DN $\left(\mathrm{CD} 4^{-} \mathrm{CD}^{-}\right)$cells but no variations in the proportions of both $\mathrm{DP}\left(\mathrm{CD} 4^{+} \mathrm{CD} 8^{+}\right)$and SP thymocytes $\left(\mathrm{CD} 4^{+} \mathrm{CD} 8^{-}\right.$and $\left.\mathrm{CD}^{-}{ }^{-} \mathrm{CD} 8^{+}\right)(20)$ and an analysis on the EphB-deficient TCR repertoire only found increased percentages of $\mathrm{VB} 3^{+} \mathrm{CD} 4^{+}$cells in thymus and lymph nodes (14). In periphery, no changes occurred in the proportions of mutant Th1, Th2, and Th17 as compared to the values of WT cell populations, and only regulatory T-cells (Treg) of the inguinal lymph nodes, but not of spleen or thymus, showed significantly higher values as compared to WT ones $(13,19)$. Remarkably, the evaluation of the frequencies of positive and negative selected thymocytes of EphB-deficient thymuses did not exhibit significant differences with respect to WT proportions $(13,19)$. Nevertheless, as demonstrated in other experimental models (9), a role for thymic DCs in the maintenance of T-cell tolerance in all these mutants cannot be discarded.

\section{CHANGES IN THE NUMBER OF TECS AFFECT BOTH THYMIC GROWTH AND THYMOCYTE DIFFERENTIATION}

In order to test the hypothesis that reduced T-TEC crosstalk would support thymocyte differentiation, as others had pointed out $(21,22)$, we recently analyzed by flow cytometry the Tcell maturation in RTOCs containing different numbers of E14.5 thymic stromal cells (TSCs) $\left(1-0.085 \times 10^{6}\right) 1$ month after grafting under the kidney capsule of FoxN1-/- mice (19). Reaggregates were performed from E14.5 WT thymic lobes receiving for 7 days $2^{\prime}$-dGuo that eliminate any dividing thymic cell. At 1 month, RTOCs established with $1-0.5 \times$ $10^{6}$ stromal cells grew in vivo around 5-7 times, but those containing lower numbers of TSC yielded significantly less thymic cells. In addition, the RTOCs established with low numbers of TSCs, mainly those containing $0.085 \times 10^{6}$ TSCs, exhibited significantly reduced proportions of $\mathrm{DP}\left(\mathrm{CD} 4^{+} \mathrm{CD} 8^{+}\right)$ cells and increased percentages of $\mathrm{CD} 4^{+}$thymocytes. In addition, there were higher frequencies of TCR $\alpha \beta^{\text {hi }}$ thymocytes, including both TCR $\alpha \beta^{\text {hi }} \mathrm{CD} 4^{+}$and TCR $\alpha \beta^{\text {hi }} \mathrm{CD}^{+}$cells, but no differences in the percentages of total positively selected thymocytes $\left(\mathrm{TCR} \alpha \beta^{\text {hi }} \mathrm{CD} 69^{+}\right)$were seen, although the frequencies of total thymic Treg cells increased (19).

\section{CONCLUSIONS AND FURTHER RESEARCH}

In summary, these results support our proposal that reduced, but not total, disappearance of T-TEC crosstalk, due to alterations in the formed thymic epithelial network formed by low numbers of TECs may be enough for supporting T-cell differentiation; below those levels a normal $\mathrm{T}$ lymphopoiesis seems to be impossible. Nevertheless, functional studies and the determination of the condition of the negative selection in these RTOCs, not analyzed in these preliminary studies, are necessary to accomplish these results. However, it seems obvious that to establish the minimal numbers of thymocytes and TECs to obtain functional immunocompetent cells may represent a promising tool to modulate central tolerance and to avoid autoimmunity. 


\section{AUTHOR CONTRIBUTIONS}

SM-H, JG-C, and AGZ: investigation and manuscript writing. AGZ: funding acquisition. All authors accept the published version of the manuscript.

\section{FUNDING}

This research was funded by the Spanish Ministry of Science, Innovation, and Universities (RTI2018-093938-B-I00), the

\section{REFERENCES}

1. Passos GA, Mendes-da-Cruz DA, Oliveira EH. The thymic orchestration involving aire, miRNAs, and cell-cell interactions during the induction of central tolerance. Front Immunol. (2015) 6:352. doi: 10.3389/fimmu.2015.00352

2. Cheng M, Anderson MS. Thymic tolerance as a key brake on autoimmunity. Nat Immunol. (2018) 19:659-64. doi: 10.1038/s41590-018-0128-9

3. Revest JM, Suniara RK, Kerr K, Owen JJ, Dickson C. Development of the thymus requires signaling through the fibroblast growtha factor receptor R2-IIIb. J Immunol. (2001) 167:1954-61. doi: 10.4049/jimmunol.167.4.1954

4. Senoo M, Pinto F, Crum CP, McKeon F. p63 is essential for the proliferative potential of stem cells in stratified epithelia. Cell. (2007) 129:52336. doi: 10.1016/j.cell.2007.02.045

5. Mao B, Niehrs C. Kremen2 modulates Dickkopf2 activity during Wnt/LRP6 signaling. Gene. (2003) 302:179-83. doi: 10.1016/S0378-1119(02)01106-X

6. Davidson G, Mao B, del Barco Barrantes I, Niehrs C. Kremen proteins interact with Dickkopf1 to regulate anteroposterior CNS patterning. Development. (2002) 129:5587-96. doi: 10.1242/dev.00154

7. Osada M, Ito E, Fermin HA, Vazquez-Cintron E, Venkatesh T, Friedel $\mathrm{RH}$, et al. The Wnt signaling antagonist Kremen1 is required for development of thymic architecture. Clin Dev Immunol. (2006) 13:299319. doi: 10.1080/17402520600935097

8. Benz C, Heinzel K, Bleul CC. Homing of immature thymocytes to the subcapsular microenvironment within the thymus is not an absolute requirement for T cell development. Eur J Immunol. (2004) 34:365263. doi: 10.1002/eji.200425248

9. Cosway EJ, Lucas B, James KD, Parnell SM, Carvalho-Gaspar M, White AJ, et al. Redefining thymus medulla specialization for central tolerance. J Exp Med. (2017) 214:3183-95. doi: 10.1084/jem.20171000

10. Inglesfield S, Cosway EJ, Jenkinson WE, Anderson G. Rethinking thymic tolerance: lessons from mice. Trends Immunol. (2019) 40:279-91. doi: 10.1016/j.it.2019.01.011

11. Wilkinson DG. Regulation of cell differentiation by Eph receptor and ephrin signaling. Cell Adh Migr. (2014) 8:339-48. doi: 10.4161/19336918.2014.970007

12. Garcia-Ceca J, Alfaro D, Montero-Herradon S, Tobajas E, Munoz JJ, Zapata AG. Eph/Ephrins-mediated thymocyte-thymic epithelial cell interactions control numerous processes of thymus biology. Front Immunol. (2015) 6:333. doi: 10.3389/fimmu.2015.00333

13. Munoz JJ, Garcia-Ceca J, Montero-Herradon S, Sanchez Del Collado B, Alfaro D, Zapata A. Can a proper T-Cell development occur in an altered thymic epithelium? Lessons from EphB-deficient thymi. Front Endocrinol. (2018) 9:135. doi: 10.3389/fendo.2018.0 0135
Carlos III Health Institute (RD16/0011/0002, Cell Therapy Network, TERCEL) and the Regional Government of Madrid (S2017/BMD-3692, Avancell).

\section{ACKNOWLEDGMENTS}

We thank the Cytometry and Fluorescence Microscopy and Animal Housing Centers of Complutense University for the use of their facilities.

14. Muñoz JJ, Alfaro D, García-Ceca J, Cejalvo T, Stimamiglio MA, Jiménez E, et al. Eph and ephrin: key molecules for the organization and function of the thymus gland. Inmunología. (2009) 28:19-31. doi: 10.1016/S0213-9626(09)70024-1

15. García-Ceca J, Jiménez E, Alfaro D, Cejalvo T, Muñoz JJ, Zapata AG. Cellautonomous role of EphB2 and EphB3 receptors in the thymic epithelial cell organization. Eur J Immunol. (2009) 39:2916-24. doi: 10.1002/eji.200939437

16. Hendrix TM, Chilukuri RV, Martinez M, Olushoga Z, Blake A, Brohi M, et al. Thymic nurse cells exhibit epithelial progenitor phenotype and create unique extra-cytoplasmic membrane space for thymocyte selection. Cell Immunol. (2010) 261:81-92. doi: 10.1016/j.cellimm.2009.11.004

17. Alfaro D, Garcia-Ceca JJ, Cejalvo T, Jimenez E, Jenkinson EJ, Anderson G, et al. EphrinB1-EphB signaling regulates thymocyte-epithelium interactions involved in functional T cell development. Eur J Immunol. (2007) 37:2596605. doi: 10.1002/eji.200737097

18. Alfaro D, Munoz JJ, Garcia-Ceca J, Cejalvo T, Jimenez E, Zapata AG. The Eph/ephrinB signal balance determines the pattern of T-cell maturation in the thymus. Immunol Cell Biol. (2011) 89:844-52. doi: 10.1038/icb.2010.172

19. García-Ceca J, Montero-Herradón S, Zapata AG. Intrathymic selection and defects in the thymic epithelial cell development. Cells. (2020) 9:2226. doi: 10.3390/cells9102226

20. Alfaro D, Munoz JJ, Garcia-Ceca J, Cejalvo T, Jimenez E, Zapata A. Alterations in the thymocyte phenotype of EphB-deficient mice largely affect the double negative cell compartment. Immunology. (2008) 125:13143. doi: 10.1111/j.1365-2567.2008.02828.x

21. Jenkinson WE, Rossi SW, Parnell SM, Jenkinson EJ, Anderson G. PDGFRalpha-expressing mesenchyme regulates thymus growth and the availability of intrathymic niches. Blood. (2007) 109:954-60. doi: 10.1182/blood-2006-05-023143

22. Prockop SE, Petrie HT. Regulation of thymus size by competition for stromal niches among early T cell progenitors. J Immunol. (2004) 173:160411. doi: $10.4049 /$ jimmunol.173.3.1604

Conflict of Interest: The authors declare that the research was conducted in the absence of any commercial or financial relationships that could be construed as a potential conflict of interest.

Copyright (c) 2021 Montero-Herradón, García-Ceca and Zapata. This is an openaccess article distributed under the terms of the Creative Commons Attribution License (CC BY). The use, distribution or reproduction in other forums is permitted, provided the original author(s) and the copyright owner(s) are credited and that the original publication in this journal is cited, in accordance with accepted academic practice. No use, distribution or reproduction is permitted which does not comply with these terms. 